\title{
O DESAFIO DA CONSTRUÇÃO DEMOCRÁTICA DO CURRÍCULO: EXPERIÊNCIA DO MUNICÍPIO DE ALMIRANTE TAMANDARÉ/PR
}

\author{
EL DESAFÍO DE LA CONSTRUCCIÓN DEMOCRÁTICA DEL CURRÍCULO: \\ EXPERIENCIA EM EL MUNICIPIO DE ALMIRANTE TAMANDARÉ/PR
}

\author{
THE CURRICULUM DEMOCRATIC CONSTRUCTION CHALLENGE: EXPERIENCE \\ IN THE MUNICIPALITY OF ALMIRANTE TAMANDARÉ/PR
}

\author{
Tatiana Tomal Brondani dos SANTOS ${ }^{1}$ \\ Raquel Eugenio de SOUZA ${ }^{2}$ \\ Hilda Alberton de CARVALHO ${ }^{3}$
}

RESUMO: O objetivo do artigo é apresentar uma iniciativa de construção democrática do currículo por uma rede pública municipal de educação, na cidade de Almirante Tamandaré/PR, Brasil. A pesquisa de natureza qualitativa traz reflexões que se pautam em uma pesquisa participante associada a uma análise documental baseada em documento da administração municipal. São descritas as etapas implementadas do programa "Caravana da Educação", envolvendo mais de 519 pessoas de diferentes segmentos da comunidade escolar na reflexão e construção coletiva do currículo, para a rede municipal de ensino, em uma perspectiva de educação integral. Desafios constantes são enfrentados pela rede pública municipal de ensino e exigem planejamento e decisões coletivas para a formação de cidadãos críticos e participativos. O currículo construído democraticamente, a exemplo de Almirante Tamandaré, torna-se um instrumento importante no enfrentamento de tal desafio.

PALAVRAS-CHAVE: Currículo. Construção democrática. Educação. Território.

RESUMEN: El objetivo del artículo es presentar una iniciativa para la construcción democrática del currículo por una red pública de educación municipal, en la ciudad de Almirante Tamandarél PR, Brasil. La investigación cualitativa trae reflexiones que parten de una investigación participativa asociada a un análisis documental a partir de un documento de la administración municipal. Se describen las etapas implementadas en el programa "Caravana da Educação", involucrando a más de 519 personas de diferentes segmentos de la comunidad escolar en la reflexión y construcción colectiva del currículo, para el sistema escolar municipal, en una perspectiva de educación integral. Los desafios constantes que enfrenta el sistema de escuelas públicas municipales requieren de planificación y decisiones colectivas para la formación de ciudadanos críticos y participativos. El currículo construido

${ }^{1}$ Universidade Tecnológica Federal do Paraná (UTFPR), Curitiba - PR - Brasil. Mestranda no Programa de Pósgraduação em Planejamento e Governança Pública. ORCID: https://orcid.org/0000-0002-7248-8581. E-mail: tatitomal@gmail.com

${ }^{2}$ Universidade Tecnológica Federal do Paraná (UTFPR), Curitiba - PR - Brasil. Mestranda no Programa de Pósgraduação em Planejamento e Governança Pública. ORCID: https://orcid.org/0000-0002-7592-5951. E-mail: raquel.eusouza@gmail.com

${ }^{3}$ Universidade Tecnológica Federal do Paraná (UTFPR), Curitiba - PR - Brasil. Diretora de Avaliação e Ouvidora Geral e Docente no Programa de Pós-graduação em Planejamento e Governança Pública. Doutorado em Tecnologia (UTFPR). ORCID: https://orcid.org/0000-0002-0693-7377. E-mail: hilda@utfpr.edu.br

RPGE- Revista on line de Política e Gestão Educacional, Araraquara, v. 25, n. 1, p. 123-137, jan./abr. $2021 . \quad$ e-ISSN:1519-9029 
democráticamente, como el de Almirante Tamandaré, se convierte en un instrumento importante para afrontar ese desafio.

PALABRAS CLAVE: Plan de estudios. Construcción democrática. Educación. Territorio.

ABSTRACT: The objective of the article is to present an initiative for the democratic construction of the curriculum by a public municipal education network, in the city of Almirante Tamandaré/ PR, Brazil. The qualitative research brings reflections that are based on participatory research associated with a document analysis based on a document from the municipal administration. The stages implemented in the "Caravana da Educação" program are described, involving more than 519 people from different segments of the school community in the reflection and collective construction of the curriculum, for the municipal school system, from a perspective of integral education. Constant challenges are faced by the municipal public school system and require planning and collective decisions for the formation of critical and participative citizens. The democratically constructed curriculum, like in Almirante Tamandaré, becomes an important instrument in facing such a challenge.

KEYWORDS: Curriculum. Democratic construction. Education. Territory.

\section{Introdução}

A construção coletiva do currículo no contexto da Educação Básica pública constituise no tema central deste artigo. Sendo assim, o nosso objetivo principal consiste em apresentar os processos que compõem uma iniciativa de construção democrática do currículo, desenvolvidos por uma rede pública municipal de ensino. Cabe destacar, inicialmente, que este trabalho se configura em uma versão revisada e ampliada de estudo desenvolvido por Santos, Souza e Carvalho (2020), intitulado "O desafio da construção democrática do currículo: experiência do município de Almirante Tamandaré, Paraná", apresentado no I Colóquios de Políticas e Gestão da Educação, organizado pela UFSCAR/Sorocaba, em 2020, e publicado nos anais do evento.

A escolha metodológica ancora-se na abordagem qualitativa e pauta-se em um caso de estudo que busca analisar as práticas vivenciadas no contexto da rede pública municipal de educação do município de Almirante Tamandaré, Estado do Paraná, Brasil. Essa instituição está desenvolvendo o programa intitulado "Caravana da Educação" que promove a participação coletiva crítica de diferentes atores na construção de um novo currículo que será implementado em sua rede de ensino. A pesquisa documental, pautada em documento próprio da Secretaria Municipal de Educação e Cultura analisada, alia-se a uma pesquisa participante por meio de observações e considerações provenientes da atuação de uma das autoras no contexto estudado.

RPGE- Revista on line de Política e Gestão Educacional, Araraquara, v. 25, n. 1, p. 123-137, jan./abr. 2021. e-ISSN:1519-9029 
Este estudo justifica-se pelo caráter contributivo teórico sob a perspectiva de demonstrar a importância da participação dos diferentes atores envolvidos no processo educacional, na reflexão e construção do currículo escolar em prol da garantia da qualidade do processo de ensino e aprendizagem. A sua contribuição prática reside no fornecimento de elementos acerca da experiência prática de Almirante Tamandaré, que podem contribuir com outras instituições na perspectiva da promoção de uma reflexão coletiva na construção do currículo.

O artigo foi organizado em quatro seções, além da introdução. A próxima seção aborda características da escola pública na atualidade. Em seguida, são apresentadas as especificidades e a importância da gestão democrática no processo educacional. Posteriormente, apresenta-se a experiência prática do município de Almirante Tamandaré na construção coletiva do currículo, por meio do programa "Caravana da Educação". Por fim, a última seção discorrerá sobre as considerações finais da pesquisa.

\section{A escola pública na atualidade}

A escola pública brasileira atual é caracterizada pelo seu dualismo, enquanto escola do acolhimento social para os pobres e do conhecimento para os ricos. O agravamento desse dualismo nos últimos anos, reproduzindo e mantendo as desigualdades sociais, possui vínculos com as reformas educativas promovidas por meio das políticas neoliberais, iniciadas nos anos 1980. Tal contexto representa substantivas explicações para o incessante declínio da escola pública brasileira nos últimos 30 anos (LIBÂNEO, 2012).

Após 1990, com a reestruturação do capitalismo, observa-se a correlação dos interesses das políticas públicas educacionais no Brasil aos interesses do capital, agora globalizado e representado pelas agências internacionais. Essas passam a orientar as reformas políticas adotadas pelos países periféricos, dentre elas as reformas educacionais. Com isso, apesar da existência de instâncias colegiadas e da obrigatoriedade da gestão democrática, observa-se que os interesses da escola ainda estão ligados às necessidades capitalistas e não aos reais interesses da sociedade (BOGATSCHOV et al., 2012).

Inserida nesse contexto, a sociedade atual apresenta posições diversas sobre os objetivos e as funções da escola no Brasil. Além disso, as políticas oficiais demonstram um pensamento quase hegemônico sobre as funções da escola pública, assentado nas políticas educativas do Banco Mundial voltada aos países em desenvolvimento. Com essa mercantilização da educação, alguns aspectos ligados a fatores intraescolares, e que afetam 
diretamente a qualidade da aprendizagem, não são priorizados, caracterizando o atual quadro sombrio da escola pública (LIBÂNEO, 2012).

Conforme Frigotto et al. (2019), a subordinação dessas políticas às determinações de organismos internacionais, tais como Banco Mundial e Fundo Monetário Internacional (FMI), deixam em segundo plano as especificidades da história brasileira na proposição das políticas públicas de educação.

Diante dessa realidade que se apresenta, em um contexto de subordinação da educação à lógica do mercado e do capital, fazem-se necessárias novas propostas que visem à mudança. Torna-se necessário pensar e construir políticas educacionais que tenham suas bases na escola e foco na aprendizagem dos estudantes, garantindo assim a melhor qualidade de ensino. Conforme Mészáros (2008), para a criação de uma diferente alternativa educacional, faz-se necessário romper com essa lógica do capital.

\section{A organização da educação escolar no Brasil em uma perspectiva democrática}

A escola é uma instituição social que pode ser considerada um lócus privilegiado de produção sistematizada do saber. Tem como principal finalidade a formação de sujeitos concretos: participativos, críticos e criativos, por meio da apropriação do saber historicamente produzido. Para isso a escola precisa estar organizada de maneira a permitir suas ações educativas (OLIVEIRA; MORAES; DOURADO, 2008).

A concepção de gestão democrática da educação, princípio constitucional estabelecido a partir da Constituição Federal de 1988, representa um importante avanço normativo para a democratização da sociedade e da educação brasileira (ALVES; ALVES; VIEGAS, 2020). Determinou uma reorganização da educação pública, visando um modelo cooperativo e colaborativo que possibilite a participação social nas decisões, promovendo uma descentralização dos poderes. Complementarmente, a Lei de Diretrizes e Bases da Educação Nacional $\mathrm{n}^{\circ}$ 9394/1996, a regulamentou e fortaleceu os mecanismos para efetivação da participação da comunidade na escola (BRASIL, 1996).

Diferentemente da administração voltada a uma empresa, que trabalha com meios tangíveis, a administração escolar possui como objeto um elemento humano e, portanto, precisa utilizar meios distintos para atingir sua finalidade. Assim a administração escolar, em uma concepção democrática, efetiva-se mediante participação dos diversos atores sociais na gestão da escola e na luta pela superação da forma como a sociedade está organizada, contrapondo-se à centralização do poder (OLIVEIRA; MORAES; DOURADO, 2008). 
Assumir a gestão democrática é um desafio, visto que o Brasil está construindo a sua democracia em um movimento contínuo e ainda não acabado. Apesar da legislação assegurar a existência das instâncias colegiadas para a participação da comunidade escolar, isso ainda não se concretizou em muitas escolas (BOGATSCHOV et al., 2012). Cabe ao gestor da escola o papel de promover essa sinergia pedagógica em sua equipe para atender às demandas educacionais da sociedade dinâmica em que estão inseridos, compreendendo o papel da escola enquanto instituição social em uma constante relação integrada com a comunidade (LUCK, 1997).

Um exemplo das experiências promovidas pela gestão democrática é a elaboração do Projeto Político Pedagógico (PPP) e do currículo nas unidades escolares. Conforme Veiga (2002) a construção do PPP de uma escola pode ser entendida como a própria organização do trabalho pedagógico e tem a ver com a organização da sociedade como um todo. $\mathrm{O}$ currículo envolve a interação entre sujeitos com um mesmo objetivo e com um referencial teórico de base. Refere-se à organização e construção coletiva do conhecimento escolar e envolve os processos de produção, transmissão e assimilação do conhecimento (VEIGA, 2002).

\section{O caso de estudo: Situando o contexto da rede pública municipal de ensino de Almirante Tamandaré}

Antes de discorrer sobre o objeto empírico deste estudo, para sua melhor compreensão, faz-se necessário situar o contexto da organização atual da rede pública municipal de ensino de Almirante Tamandaré. Destaca-se que todo o processo que será descrito na sequência foi idealizado pelos gestores que assumiram a Secretaria Municipal de Educação e Cultura (SMEC) do município em janeiro de 2017, e que permanecem nessa função até o momento.

Almirante Tamandaré localiza-se na Região Metropolitana de Curitiba, a uma distância de $15 \mathrm{~km}$ da capital. Grande parte de seus habitantes exerce suas atividades produtivas em Curitiba, apenas residindo na cidade, o que desfavorece a circulação de renda local. Nota-se a construção de um cenário de desigualdades, com parcela significativa da população em situação de vulnerabilidade social. A inclusão do município na região metropolitana, apesar de favorecer um maior dinamismo econômico, não diminuiu a distância socioeconômica qualitativa que o separa do polo (KORNIN; CARMO, 2013). Na expectativa de elevação em sua qualidade de vida, muitos cidadãos tamandareenses vivem o sonho de residir na capital vizinha. 
Conforme Oliveira (2015) os municípios possuem a incumbência de ordenação e desenvolvimento social, bem como de prover o bem-estar de sua população, promovendo políticas públicas com vistas à efetivação democrática do poder público. A atual administração de Almirante Tamandaré compreende a necessidade de formulação de políticas públicas que dialoguem com a realidade local visando a promoção de melhoria da qualidade de vida da população e o desenvolvimento local sustentável. Defende ainda o papel fundamental da educação no desenvolvimento de um senso de pertencimento dos jovens ao município.

Para tal, as políticas educacionais no município, desde o ano de 2017 , vem sendo planejadas em uma perspectiva territorial de promoção de uma educação integral. Fomentadas pelos atuais gestores da SMEC, com ampla discussão e construção coletiva entre os diversos atores envolvidos, articulando-se toda a sociedade nesse processo, o que culminou na implementação dos cinco Territórios dos Saberes.

Assim, as políticas educacionais municipais em Almirante Tamandaré foram reorganizadas em uma nova perspectiva territorial. Esses territórios foram organizados visando identificar similaridades identitárias entre os grupos populacionais do município que permitissem o agrupamento em distintos territórios de acordo com suas especificidades. Como critérios, foram utilizados, além de aspectos geográficos, também aspectos culturais, históricos, migratórios, econômicos, de mobilidade urbana, bem como a organização dos diferentes poderes que influenciam esses territórios.

Segundo Arruda e Goulart (2017), o potencial educativo do território está relacionado com a concepção de Cidade Educadora. A territorialização da educação ocorre com a abertura da escola para a comunidade que passa a compreender o território como lugar de relações de vida e não apenas uma estrutura física. Estabelecem-se novos pactos, entre sociedade e escola, de responsabilização pela educação.

Essa reorganização das políticas educacionais do município promoveu uma maior integração da escola com o território em que se situa. Ao compreender que o estudante é formado também fora da escola, propiciaram-se novas oportunidades pedagógicas que consideram a existência, além do saber científico, também destes novos saberes da comunidade. Pois, conforme Libâneo (2012), é necessário apostar em uma escola que articule as diferenças, valores e formas de conhecimento local e cotidiano à formação cultural e cientifica. Torna-se necessário o acolhimento da diversidade cultural em uma escola para todos. 
Nesse contexto plural, a proposta da educação integral busca ligar a escola ao seu entorno, ampliando tempos, espaços, sujeitos e oportunidades educativas, considerando saberes populares no projeto pedagógico (ARRUDA; GOULART, 2017). Assim, ao entender o sujeito como detentor de direitos e articulado ao território que vivencia, não havia outra possibilidade para o município, além de planejar suas políticas educacionais respeitando-se a questão espacial e territorial.

A estratégia dos Territórios dos Saberes torna possível a garantia da promoção do desenvolvimento integral do educando, ao se considerar o território enquanto espaço privilegiado de aprendizagens. Nessa dinâmica, a educação integral considera a importância do diálogo das unidades educacionais com o território no intuito de gerar, a longo prazo, uma relação de identidade e de pertencimento local ao cidadão tamandareense, rompendo, assim, com o drama do sonho da capital.

Para tornar isso possível, o município defende que o currículo precisa ser construído coletivamente, democraticamente, e alinhado ao território e a comunidade local. Esse é um dos propósitos da fase atual das políticas educacionais do município, a implementação do programa da "Caravana da Educação". Tal propósito corrobora com Veiga (2002), que defende que o currículo é um importante elemento constitutivo da organização e construção social coletiva do conhecimento escolar. Como tal, não pode ser considerado um instrumento neutro e não pode ser separado do contexto social, pois é historicamente situado e culturalmente determinado.

\section{O programa "Caravana da Educação": Uma proposta de construção coletiva do currículo municipal}

Esta seção apresentará o desafio do processo de reflexão e construção democrática do novo currículo da rede pública municipal de educação de Almirante Tamandaré. Para isso serão descritos os principais pontos observados e vivenciados em tal dinâmica, enquanto servidora pública atuante no contexto estudado, somados às informações contidas no documento Relato de Memória Programa "Caravana da Educação".

O programa "Caravana da Educação" possui como princípio a perspectiva democrática. Representa uma iniciativa idealizada pelos atuais gestores da SMEC em parceria com os demais servidores, visando impulsionar os debates em torno da construção coletiva do novo currículo da rede municipal de ensino, que terá como concepção a Educação Integral. Defende-se que somente pelo viés democrático é possível construir um currículo na 
perspectiva da educação integral, articulado com o território e que dê conta de materializar a proposta prática. A existência dos Territórios dos Saberes em Almirante Tamandaré potencializa esse programa, pois se constitui em um plano educativo local com a intencionalidade de operacionalizar a política de educação integral no território, articulando toda a sociedade.

A Educação Integral considera a educação, enquanto instrumento socializador, indispensável para a coesão comunitária e pessoal. Defende que somos todos responsáveis pela educação, a qual deixa de limitar-se apenas à educação escolar formal e compreende o território enquanto espaço privilegiado de aprendizagens. Pressupõe a construção de redes para o desenvolvimento humano integral dos sujeitos (ARRUDA; GOULART, 2017).

Com a "Caravana da Educação", o município pretende "escutar/falar com todos" os diversos atores envolvidos com o processo educacional em cada território. Busca-se, com isso, o compartilhamento dos diferentes saberes entre profissionais da educação e sociedade civil para ampliar a compreensão de educação pública e da possibilidade de intervir sobre ela, na busca de efetivar os direitos de aprendizagem aos educandos.

Almirante Tamandaré compreende atualmente que não é somente a escola que "ensina" e que o conteúdo proposto nesta perspectiva fica sem sentido e não mobiliza os educandos. Defende que a construção do novo currículo só terá sentido se for concebido democraticamente para que se torne capaz de responder às demandas do século XXI. Isso é fundamental para que se torne um instrumento capaz de formar sujeitos humanizados, críticos, autônomos e responsáveis consigo mesmo e com o mundo (PMAT, 2019).

Para a construção do novo currículo da rede, a metodologia utilizada foi a realização de rodas de conversas sobre a educação, embasando-se na pedagogia freiriana. Buscou-se a utilização de métodos reflexivos e diversos de acordo com cada segmento ouvido: profissionais da educação, famílias, lideranças religiosas, comerciantes locais, educandos e lideranças do bairro. A intenção principal foi promover a reflexão sobre educação e levantar subsídios e propostas a serem contempladas na construção do novo currículo da rede municipal de ensino, articulado com a realidade da cidade (PMAT, 2019).

Frente à grande troca de conhecimentos promovida, a necessidade de replanejamento tornou-se constante. Assim, por meio da tríade "reflexão-ação-reflexão", a metodologia utilizada foi redefinindo-se no decorrer das vivências, visando sempre a ampliação da qualidade e participação, prezando-se pelo viés democrático (PMAT, 2019). Dada a incapacidade de executar esse programa em todos os territórios ao mesmo tempo, optou-se em 
gradativamente percorrer o município, iniciando-se pelo Território 01 . Referente ao processo ocorrido na implementação do programa nesse território que este estudo discorrerá.

Para o alinhamento das concepções e conceitos que permearão o novo currículo, foram realizadas quatro reuniões com a equipe interna da SMEC, entre os meses de fevereiro a junho de 2019. No entanto, no cotidiano a troca de experiências e reflexões mantem-se constantes entre toda a equipe. Em seguida, realizaram-se dois encontros de alinhamento geral com os 14 profissionais que compõem as duplas gestoras das unidades educacionais do Território 1, em maio de 2019. Também foi promovido, em junho de 2019, um encontro de alinhamento envolvendo os demais profissionais da educação deste território, totalizando 83 profissionais (PMAT, 2019).

Nessas reuniões buscou-se possibilitar que todos recebessem as informações necessárias para a participação ativa na construção do novo currículo bem como apresentar e definir como seria desenvolvida a "Caravana da Educação". Após essa etapa, iniciaram-se os diversos momentos de diálogo com distintos segmentos envolvidos no processo educacional das sete unidades educacionais do Território.

Uma primeira ação de diálogo que se destaca envolveu os educandos dessas unidades, por meio de assembleias infantis. Esse diálogo dividiu-se em três momentos: a) Diálogo com os educandos selecionados por amostragem, em uma turma de cada unidade educacional do Território 1; b) Diálogo com todas as turmas de cada unidade educacional oportunizado pelas duplas gestoras; c) Diálogo de educandos, selecionados por amostragem, com o Secretário Municipal da Educação e Cultura (PMAT, 2019).

Destaca-se a importância de manifestação desses atores, aos quais, ao longo da história, raramente são oportunizados espaços para a escuta, sempre centralizada nos adultos. Também de grande importância foi a participação intensiva do Secretário Municipal da Educação, diretamente envolvido na vivência do diálogo com os educandos, bem como também na grande maioria dos demais diálogos propostos. Tal aspecto enfatiza a escolha do município pelo viés democrático que permeia todas as instâncias do Programa.

Uma segunda ação foi o diálogo com 98 profissionais da educação do Território 1, somados a 57 profissionais que compõe a SMEC. Os encontros ocorreram nas próprias unidades educacionais e em dois momentos distintos, totalizando 14 encontros. Em um primeiro encontro, todos os profissionais foram convidados democraticamente a compartilhar suas vivências, trajetórias profissionais e visão do território onde estão inseridos, no intuito de articular a prática à realidade de cada educando (PMAT, 2019). 
O segundo momento envolveu aplicação da Análise F.O.F.A.: Forças, Oportunidades, Fraquezas e Ameaças da unidade educacional e território como um todo, possibilitando olhar o Território nas quatro dimensões analisadas. A escolha desta técnica justificou-se pela ampliação do leque de possibilidades de análise a partir do contexto em que os profissionais estão inseridos. Como resultado desta etapa, observou-se a construção coletiva de um grande panorama da realidade local que contribuirá para futuras tomadas de decisões por parte de todos, tanto da própria unidade educacional quanto da SMEC (PMAT, 2019).

Uma terceira proposta de diálogo foi realizada com as famílias dos educandos das sete unidades educacionais do território 1, envolvendo um total de 270 participantes distribuídos em sete encontros distintos que ocorreram em cada unidade educacional. Os encontros ocorreram entre os meses de julho a agosto de 2019 e envolveram reflexões, principalmente, no que se refere à gestão da aprendizagem dos educandos. Para finalizar a etapa do diálogo com os familiares, ocorreu uma assembleia com todas as famílias de educandos do Território 1, em setembro de 2019, envolvendo 128 participantes. Esse encontro coletivo foi projetado a partir das vivências da etapa anterior (PMAT, 2019).

Um quarto momento de diálogo promovido teve um caráter inter-religioso, envolvendo diversas representatividades religiosas do Território 1. Foi proposta uma reflexão sobre a educação pública e o papel dos espaços sagrados na articulação com a educação da cidade. Esse encontro envolveu 22 participantes e ocorreu em setembro de 2019. A importância da escuta deste segmento deve-se ao fato que Almirante Tamandaré entende que os educandos precisam conviver em um espaço de garantia do direito à liberdade religiosa. Por isto existe a necessidade deste diálogo para gerar propostas pertinentes à construção do novo currículo da rede e, ao mesmo tempo, convidar as lideranças religiosas para que se fortaleçam enquanto educadores e se tornem parceiros das unidades educacionais (PMAT, 2019).

Um quinto diálogo promovido ocorreu com 34 representantes das Associações de Pais e Mestres (APMFs) das unidades educacionais do território, em outubro de 2019. Este encontro foi também decisivo para esclarecimentos pertinentes à função da APMF e da importância deste colegiado frente a gestão democrática da aprendizagem dos educandos. Entendendo que o envolvimento da comunidade escolar é essencial na perspectiva da construção coletiva e democrática do novo currículo da rede, além do diálogo com as APMFs, promoveu-se também um sexto momento de diálogo, envolvendo 25 representantes dos Conselhos Escolares das unidades do Território 1, também em outubro de 2019. Compreendendo-se a importância dos mesmos como órgãos máximos na tomada de decisões 
realizadas no interior da unidade educacional, destacou-se a sua importância em relação a aprovação dos PPPs das unidades educacionais (PMAT, 2019).

Um sétimo diálogo proposto foi com os pequenos empresários do Território 01, formalizando-se dois encontros, que contaram com quatro comerciantes locais cada. A proposta foi convidá-los a fazer parte da construção do novo currículo da rede, sensibilizando-os quanto ao seu papel enquanto espaços educadores e não apenas prestadores de serviços. Apesar do pequeno número de participantes, o encontro tornou-se muito significativo (PMAT, 2019).

Finalizando-se o ciclo da "Caravana da Educação" no Território 1, ocorreu no final de outubro de 2019, um Ciclo de Diálogos com 110 profissionais da educação, atuantes nesse Território, no intuito de fomentar novos debates em torno da construção do novo currículo da rede. Para a finalização da proposta de construção desse novo currículo, pretende-se escrever coletivamente cadernos curriculares que contemplem as reflexões geradas em cada unidade educacional e por todos os atores envolvidos (PMAT, 2019).

O processo ainda está em elaboração, mas a atual sugestão está organizada nestes nove cadernos: a) Concepções Educacionais na Perspectiva da Educação Integral; b) Legislação Comentada; c) Currículo e Educação Integral articulada aos territórios - Diálogo com a cidade; d) A singularidade de cada Território; e) Gestão Educacional - Um olhar para a Educação Integral; f) Gestão da aprendizagem a partir de múltiplos saberes; g) Avaliação do currículo em todas as dimensões do contexto educacional; h) Produção dos espaços e clima na Educação Integral; e i) Matrizes dos Saberes - a partir da legislação (PMAT, 2019). O quadro abaixo apresenta resumidamente os principais resultados encontrados no caso estudado.

Quadro 1 - Principais resultados do caso de estudo

\begin{tabular}{|l|l|l|l|}
\hline \multicolumn{1}{|c|}{ FATOR } & \multicolumn{1}{|c|}{ DEFINIÇÃO } & AUTORES & \multicolumn{1}{|c|}{$\begin{array}{c}\text { ACHADOS DO CASO DE } \\
\text { ESTUDO }\end{array}$} \\
\hline Territórios & $\begin{array}{l}\text { Território enquanto espaço privilegiado } \\
\text { de aprendizagens. }\end{array}$ & $\begin{array}{l}\text { (ARRUDA; } \\
\text { GOULART, } \\
2017)\end{array}$ & $\begin{array}{l}\text { Divisão do município em cinco } \\
\text { territórios de acordo com suas } \\
\text { especificidades. }\end{array}$ \\
\hline $\begin{array}{l}\text { Educação } \\
\text { Integral }\end{array}$ & $\begin{array}{l}\text { Educação como responsabilidade de } \\
\text { todos, promovida com valorização dos } \\
\text { distintos saberes, não se limitando } \\
\text { apenas à educação escolar formal. } \\
\text { Pressupõe a construção de redes para o } \\
\text { desenvolvimento humano integral dos } \\
\text { sujeitos. }\end{array}$ & $\begin{array}{l}\text { GOULART, } \\
2017)\end{array}$ & $\begin{array}{l}\text { Construção do currículo escolar na } \\
\text { perspectiva de educação integral } \\
\text { com formação de redes, para o } \\
\text { desenvolvimento humano integral } \\
\text { dos sujeitos, que envolvem } \\
\text { diversos atores no território. }\end{array}$ \\
\hline $\begin{array}{l}\text { Gestão } \\
\text { Democrática }\end{array}$ & $\begin{array}{l}\text { Efetiva-se mediante participação dos } \\
\text { diversos atores sociais na gestão da } \\
\text { escola e na luta pela superação da forma }\end{array}$ & $\begin{array}{l}\text { (OLIVEIRA; } \\
\text { MORAES; } \\
\text { DOURADO, }\end{array}$ & $\begin{array}{l}\text { Descentralização do público, poder } \\
\text { envolvendo articipação de diversos atores }\end{array}$ \\
\hline
\end{tabular}




\begin{tabular}{|c|c|c|c|}
\hline & $\begin{array}{l}\text { como a sociedade está organizada, } \\
\text { contrapondo-se à centralização do } \\
\text { poder. }\end{array}$ & 2008) & $\begin{array}{l}\text { sociais na construção do currículo } \\
\text { da rede pública municipal e na } \\
\text { gestão escolar. }\end{array}$ \\
\hline $\begin{array}{l}\text { Democratização } \\
\text { do poder } \\
\text { público }\end{array}$ & $\begin{array}{l}\text { Papel do município na promoção de } \\
\text { políticas públicas com vistas à } \\
\text { efetivação democrática do poder público } \\
\text { a fim de prover o bem-estar de sua } \\
\text { população. }\end{array}$ & $\begin{array}{l}\text { (OLIVEIRA, } \\
2015)\end{array}$ & $\begin{array}{l}\text { Política pública educacional que } \\
\text { dialoga com a realidade, visando } \\
\text { promoção de melhoria da } \\
\text { qualidade de vida da população e } \\
\text { o desenvolvimento local } \\
\text { sustentável. }\end{array}$ \\
\hline $\begin{array}{l}\text { Currículo } \\
\text { Escolar }\end{array}$ & $\begin{array}{l}\text { Instrumento de organização } \mathrm{e} \\
\text { construção coletiva do conhecimento } \\
\text { escolar, historicamente situado e } \\
\text { culturalmente determinado. }\end{array}$ & $\begin{array}{l}\text { (VEIGA, } \\
2002)\end{array}$ & $\begin{array}{llr}\text { Construção } & \text { crítica-reflexiva } & \text { do } \\
\text { currículo, respeitando } & \text { a } \\
\text { diversidade cultural ao envolver } & \\
\text { diversos atores do território. } & \end{array}$ \\
\hline
\end{tabular}

Fonte: Dados da Pesquisa (2019)

A tarefa de repensar e valorizar os papéis dos distintos atores no processo democrático é fundamental para as mudanças que se fazem necessárias no cenário da escola atual, onde muitas vezes observam-se currículos fragmentados (DALLA CORTE; MACHADO, 2020) e não condizentes com a realidade na qual a escola está inserida. Sabe-se que a elaboração final do currículo reserva um desafio ainda maior a ser enfrentado: alinhar as bases nacionais curriculares padronizadas pelo sistema nacional de ensino a estas realidades distintas, respeitando as especificidades diagnosticadas em cada uma delas. Mas visando a construção democrática e ligada à realidade local do currículo, esse programa se propõe a enfrentar tal desafio (PMAT, 2019).

\section{Considerações finais}

Considerando-se que a educação tem na sua efetivação o caráter de uma demanda que é pública, infere-se que a responsabilidade do Estado tanto como regulador, quanto propulsor dessa política, precisa ser reivindicada. Dessa realidade emerge a discussão sobre a importância das políticas públicas voltadas à educação, sobretudo quando consideramos a tendência que têm os organismos internacionais de determinarem condicionalidades que são aceitas pelos países dependentes. Assim, o que se observa na realidade educacional brasileira é um declínio da escola pública, orientada para os interesses do capital, desvinculada da realidade e das demandas do cotidiano escolar.

Como parte dessa dinâmica, justifica-se a necessidade de novas formas de organização do trabalho pedagógico, da gestão escolar e da participação, visando a democratização do espaço escolar. Processo que colaborará para que a escola cumpra sua função social na 
produção e disseminação do saber historicamente produzido (OLIVEIRA; MORAES; DOURADO, 2008).

É notório que os processos de gestão democrática e participação coletiva dependem dos diferentes perfis de gestores que se envolvem com menor ou maior efetividade nesses processos. Assim, a noção de mais direitos, traz também mudanças nos modos de organização e gestão educacional nos diferentes âmbitos estatais que percebem na nova gestão pública uma resposta mais democrática à sociedade (OLIVEIRA, 2015).

Nesse contexto, Almirante Tamandaré possui como potencialidade, gestores da política educacional municipal engajados na proposta da gestão democrática e que consideram a educação com um papel estratégico para repensar as políticas públicas, enquanto provocadora de uma nova política e de um novo projeto de sociedade. O município acredita que a gestão democrática seja de fato o caminho para a construção coletiva do currículo. Currículo este que não só deverá ser construído coletivamente, mas deverá estar articulado com os diversos saberes do território em uma perspectiva de promoção de educação integral.

A "Caravana da Educação", desenvolvida no município de Almirante Tamandaré/PR, pode ser considerada um instrumento de democratização da participação da comunidade na gestão pública. Nessa abertura da escola à comunidade escolar, se favorece a busca conjunta de novas estratégias para o fortalecimento da escola pública por meio do novo currículo a ser construído numa grande rede de articulação. O cidadão torna-se um autor conjunto da construção do currículo, uma vez que se possibilita, com esse programa, dar voz ao cidadão.

A rede pública municipal de ensino em todo o Brasil enfrenta desafios constantes que exigem planejamento $\mathrm{e}$ decisões coletivas para a formação de cidadãos críticos $\mathrm{e}$ participativos. Um currículo construído democraticamente, a exemplo do processo detalhado do município de Almirante Tamandaré, torna-se um instrumento importante no enfrentamento de tal desafio.

Destaca-se que durante o período da materialização da "Caravana da Educação" no Território 01, sem contabilizar os números das vivências com os educandos, foram envolvidas 519 pessoas de diversos segmentos da sociedade, em 35 encontros promovidos entre os meses de fevereiro a novembro de 2019, para a reflexão crítica em prol da construção do novo currículo para a rede pública municipal de ensino. Desta forma, a "Caravana da Educação", oportuniza a materialização da gestão democrática no município. Enfatiza o exercício de democratização da construção curricular com a pretensão de que essas ações se tornem rotina no cotidiano da educação integral e no território. Por fim, todo esse processo exige dos gestores, grande comprometimento e responsabilidade social em prol da cidadania. 


\section{REFERÊNCIAS}

ARRUDA, F.; GOULART, B. Prêmio territórios educativos: iluminando experiências na educação que ativam territórios por meio da cultura. In: AMARAL, L.; ROCHA, C. (Org). Patrimônios Possíveis: Arte, Rede e Narrativas da Memória em Contexto Iberoamericano. Goiânia: Gráfica UFG, 2017. p. 32-40. Disponível em: https://patrimoniospossiveis.medialab.ufg.br/03_felipe_arruda.html. Acesso em: 30 nov. 2019.

ALVES, A. V. V.; ALVES, A. G. R.; VIEGAS, E. R. S. A gestão educacional nos planos de educação: do nacional ao municipal. Revista Ibero-Americana de Estudos em Educação, Araraquara, v. 15, n. esp. 1, p. 719-734, 2020. DOI:

https://doi.org/10.21723/riaee.v15iesp.1.13345

BRASIL. Lei n. 9.394, de 20 de dezembro de 1996. Lei de Diretrizes e Bases da Educação Nacional. Diário Oficial da União: Seção 1, Brasília, DF, n. 248, p. 27833, 23 dez. 1996. PL $1258 / 1988$

BOGATSCHOV, D. N.; FERREIRA, G. M.; GODOY, G. A. V.; VOLSI, M. E. F.; MOREIRA, J. A. S. A escola como núcleo da gestão democrática: práticas coletivas na organização da escola a partir das instâncias colegiadas. In: SEMINÁRIO NACIONAL DE ESTUDOS E PESQUISAS, 9., 2012, João Pessoa. Anais [...]. João Pessoa, PB: UFPB, 2012. p. 2797-2813. Disponível em:

https://www.academia.edu/9355826/IX_SEMIN\%C3\%81RIO_NACIONAL_DE_ESTUDOS E_PESQUISAS_HIST $\%$ C3\%93RIA_SOCIEDADE_E_EDUCA $\%$ C $3 \% 87 \% \bar{C} 3 \% \overline{\%} 83 \mathrm{O}$ NO BRASIL_Universidade_Federal_da_Para\%C3\%ADba_Jo\%C3\%A3o_Pessoa_31_07_a_03_0 8_2012_Ānais_Eletr\% $\% \bar{C} 3 \%$ B4nicos_ISBN_978_85_7745_551_5_A. Acesso em: 30 nov. 2019.

DALLA CORTE, M. G.; MACHADO, C. M. F. Fortalecimento dos conselhos escolares no cenário da gestão democrática da rede municipal de ensino de Santa Maria - RS. Revista Ibero-Americana de Estudos em Educação, Araraquara, v. 15, n. 2, p. 522-538, abr.jun. 2020. DOI: https://doi.org/10.21723/riaee.v15i2.12093

FRIGOTTO, G.; NEVES, B. M.; BATISTA, E. G.; SANTOS, J. R. O “estado da arte” das pesquisas sobre os IFs no Brasil: a produção discente da pós-graduação - de 2008 a 2014. In: FRIGOTTO, G. (Org). Institutos Federais de Educação, Ciência e Tecnologia: Relação com o ensino médio integrado e o projeto societário de desenvolvimento. Rio de Janeiro: LPP/UERJ, 2019.

KORNIN, T.; CARMO, J. C. B. O arranjo institucional de gestão na Região Metropolitana de Curitiba. In: COSTA, M. A.; TSUKUMO, I. T. L. (Org). 40 anos de regiões metropolitanas no Brasil. Brasília: Ipea, 2013. p. 87-108.

LIBÂNEO, J. C. O dualismo perverso da escola pública brasileira: escola do conhecimento para os ricos, escola do acolhimento social para os pobres. Educ. Pesqui., São Paulo, v. 38, n. 1, p. 13-28, 2012. Disponível em:

http://www.scielo.br/scielo.php?script=sci_arttext\&pid=S1517-

97022012000100002\&lng=en\&nrm=iso. Acesso em: 30 nov. 2019. 
LÜCK, H. A evolução da gestão educacional a partir de mudança paradigmática. Gestão em Rede, Curitiba, n. 3, p. 13-18, 1997. Disponível em: http://cedhap.com.br/wpcontent/uploads/2013/09/ge_GestaoEscolar_02.pdf?inframe=yes\&iframe=true. Acesso em: 30 nov. 2019.

MÉSZÁROS, I. A educação para além do capital. 2. ed. São Paulo: Boitempo, 2008. Disponível em: http://www.gepec.ufscar.br/publicacoes/livros-e-colecoes/livros-diversos/aeducacao-para-alem-do-capital-istvan-meszaros.pdf/view. Acesso em: 30 nov. 2019.

OLIVEIRA, D. A. Nova gestão pública e governos democrático-populares: contradições entre a busca da eficiência e a ampliação do direito à educação. Educação \& Sociedade [online], Campinas, v. 36, n. 132, p. 625-646, 2015. DOI: http://dx.doi.org/10.1590/ES010173302015152440

OLIVEIRA, J. F.; MORAES, K. N.; DOURADO, L. F. Organização da educação escolar no Brasil na perspectiva da gestão democrática: sistemas de ensino, órgãos deliberativos e executivos, regime de colaboração, programas, projetos e ações. Módulo da Sala PGE. Programa escola de Gestores da Educação Básica. Goiás: UFG, 2008. Disponível em: http://moodle3.mec.gov.br/ufscar/file.php/1/gestores/politica/pdf/texto2_2.pdf. Acesso em: 30 nov. 2019.

PREFEITURA MUNICIPAL DE ALMIRANTE TAMANDARÉ - P. M. A. T. Relatório de Memória Programa Caravana da Educação. PMAT: Almirante Tamandaré, 2019.

SANTOS, T. T. B.; SOUZA, R. E.; CARVALHO, H. A. O desafio da construção democrática do currículo: experiência do município de Almirante Tamandaré, Paraná. In: COLÓQUIOS DE POLÍTICAS E GESTÃO DA EDUCAÇÃO, 1., 2020, Sorocaba. Anais [...]. Sorocaba, SP: UFSCAR, 2020. p. 472-483. Disponível em: https://laplageemrevista. ufscar.br/index.php/CPGE/article/view/879. Acesso em: 10 jun. 2020.

VEIGA, I.P. Projeto político-pedagógico da escola: uma construção coletiva. In: VEIGA, I. P. (Org.). Projeto político-pedagógico da escola: uma construção possível. 14. ed. Campinas, SP: Papirus, 2002. Disponível em: https://www.sinprodf.org.br/wpcontent/uploads/2014/01/PPP-segundo-Ilma-Passos.pdf. Acesso em: 30 nov. 2019.

\section{Como referenciar este artigo}

SANTOS, T. T. B.; SOUZA, R. E.; CARVALHO, H. A. O desafio da construção democrática do currículo: experiência do município de Almirante Tamandaré/PR. Revista on line de Política e Gestão Educacional, Araraquara, v. 25, n. 1, p. 123-137, jan./abr. 2021. eISSN:1519-9029. DOI: https://doi.org/10.22633/rpge.v25i1.14028

Submetido em: 20/04/2020

Revisões requeridas em: 30/06/2020

Aceito em: 09/11/2020

Publicado em: 02/01/2021 